\title{
Effects of Dual-Ion Irradiation on the Swelling of SiC/SiC Composites
}

\author{
Hirotatsu Kishimoto $^{1}$, Kazumi Ozawa ${ }^{2}$, Sosuke Kondo ${ }^{2}$ and Akira Kohyama ${ }^{1}$ \\ ${ }^{1}$ Institute of Advanced Energy, Kyoto University, Uji 611-0011, Japan \\ ${ }^{2}$ Graduate School Student, Graduate School of Energy Science, Kyoto University, Uji 611-0011, Japan
}

\begin{abstract}
Silicon carbide $(\mathrm{SiC})$ matrix composites reinforced by $\mathrm{SiC}$ fibers is a candidate structural material of fusion gas-cooled blanket system. From the viewpoint of material designs, it is important to investigate the swelling by irradiation, which results from the accumulation of displacement damages. In the fusion environment, $(\mathrm{n}, \alpha)$ nuclear reactions are considered to produce helium gas in SiC. For the microstructural evolution, a dual-ion irradiation method is able to simulate the effects of helium. In the present research, $1.7 \mathrm{MeV}$ tandem and $1 \mathrm{MeV}$ single-end accelerators were used for Si self-ion irradiation and helium implantation, respectively. The average helium over displacement per atom (dpa) ratio in $\mathrm{SiC}$ was adjusted to $60 \mathrm{appm} / \mathrm{dpa}$. The irradiation temperature ranged from room temperature to $1400^{\circ} \mathrm{C}$. The irradiation-induced swelling was measured by the step height method. Helium that was implanted simultaneously with displacement damages in dual-ion irradiated $\mathrm{SiC}$ increased the swelling that was larger than that by single-ion irradiated $\mathrm{SiC}$ below $800^{\circ} \mathrm{C}$. Since this increase was not observed above $1000^{\circ} \mathrm{C}$, the interaction of helium and displacement damages was considered to change above $800^{\circ} \mathrm{C}$. In this paper, the microstructural behavior and dimensional stability of $\mathrm{SiC}$ materials under the fusion relevant environment are discussed.
\end{abstract}

(Received September 24, 2004; Accepted June 3, 2005; Published August 15, 2005)

Keywords: radiation damage, microstructure, dual-ion irradiation, SiC/SiC composites, fusion

\section{Introduction}

Fusion energy is one of the most desirable candidates as future energy resources. The energy efficiency of fusion is closely related to the blanket system. A gas-cooled blanket operating above $1000^{\circ} \mathrm{C}$ using $\mathrm{SiC} / \mathrm{SiC}$ composites as structural materials is expected to attain high energy efficiency. SiC materials with excellent mechanical properties and microstructural stability at elevated temperature are required under irradiation environments. ${ }^{1)}$ It was difficult to confirm the suitability of $\mathrm{SiC} / \mathrm{SiC}$ composites as fusion materials, since the research on high-temperature irradiation effects were so limited. Other problems associated with employing $\mathrm{SiC} / \mathrm{SiC}$ composites for fusion reactors were the synergistic effects of radiation damage and helium. The nuclear reaction by $14 \mathrm{MeV}$ fast neutrons produces helium in SiC. Although the produced helium was expected to interact with the behavior of radiation damages, the precise details of correlation were unclear. ${ }^{2)}$

The heavy-ion irradiation produces the cascade damage, which is similar to that of the $14 \mathrm{MeV}$ fast neutron irradiation. The simultaneous irradiation of the heavy and helium ions is able to simulate the synergistic effects of cascade damage and helium. Thus the dual-ion irradiation method has been employed in fusion materials research. ${ }^{3)}$ The other advantages of the dual-ion irradiation method have abilities of precise temperature control in a wide temperature range, time-saving during an experiment, and no radioactivity after the irradiation experiments. The microstructural behavior of $\mathrm{SiC}$ at elevated temperatures above $1000^{\circ} \mathrm{C}$ is not well known. In this paper, the microstructural behavior and dimensional stability of $\mathrm{SiC}$ materials are investigated at very high temperatures up to $1400^{\circ} \mathrm{C}$ utilizing dual-ion irradiation facility.

\section{Experimental}

\subsection{DuET facility}

Dual-Beam Material Irradiation Facility for Energy Tech-

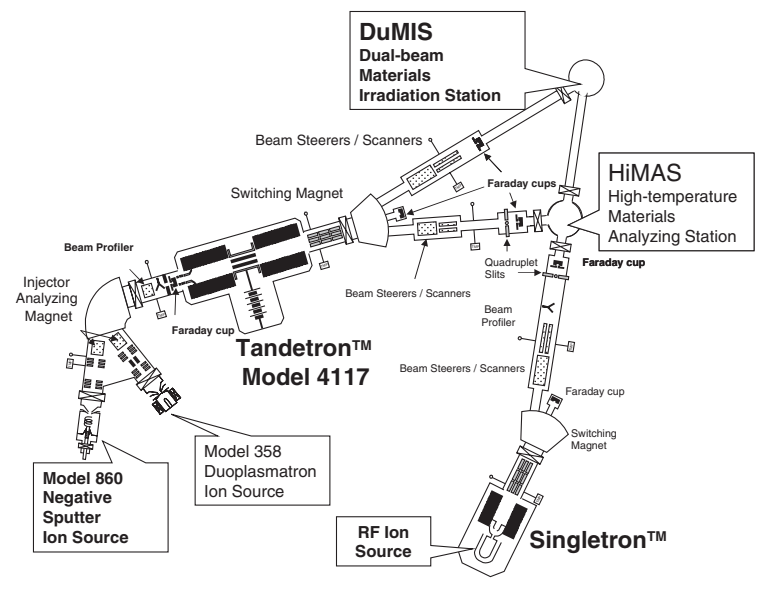

Fig. 1 Arrangement of equipments in the DuET Facility.

nology (DuET) Research Facility at the Institute of Advanced Energy, Kyoto University, was used for this research. For the irradiation experiments, the DuET facility with two accelerators, $1.7 \mathrm{MeV}$ tandem (Model 4117HC, HVEE B.V, Amersfoort, Netherlands) and $1 \mathrm{MeV}$ single-end (HVEE B.V, Amersfoort, Netherlands), and two target stations were employed. Figure 1 shows the arrangement of equipments in the DuET facility. The target stations are located at the beamline junctions of the accelerators. The beams from both the accelerators intersect at the specimen surface in the target station. The tandem accelerator has a cesium sputter negative ion source (Model 860, HVEE B.V, Amersfoort, Netherlands) for heavy-ion irradiation. Usually, the self-ion, Si ion for $\mathrm{SiC}$, is selected to eliminate the effects of heavy-ion implantation. A single-end accelerator is used for helium implantation other than Si. An energy degrader is placed in the beamline to reduce the energy of helium ions in order to stop them at an appropriate depth in the target material. The depth profiles of displacement damages and helium concentration were calculated by TRIM codes using 5.1 MeV Si and $1 \mathrm{MeV}$ helium ions as shown in Fig. 2. The implanted and 


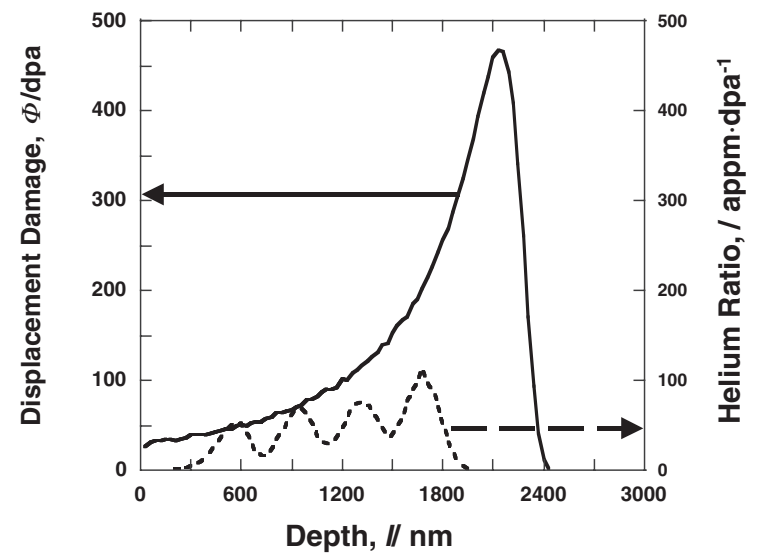

Fig. 2 Depth profiles of displacement damage and helium ratio calculated by TRIM-98.

energy degraded helium ions were widely overlapped in the damaged range due to heavy-ion irradiation. The synergistic effects of displacement damages and helium can be investigated from the microstructural behaviors in the overlapped range. Temperature control and measurement are also an important factor for analyzing the irradiation effects. Since the $\mathrm{SiC}$ research demands high temperature experiments above $1000^{\circ} \mathrm{C}$, an additional graphite carbon heater was attached to the specimen holder to realize high temperatures. A thermal-vision system (LAIRD3A, Nikon Co., Tokyo, Japan) was used for in-situ temperature measurements. The maximum temperature of this system was around $1500^{\circ} \mathrm{C}$.

\subsection{Swelling investigation of $\mathrm{SiC}^{5}$}

Monolithic (3C) $\beta$-SiC specimens produced by the chemical vapor deposition (CVD) process (Rohm and Hass Co., Woburn, USA) were used for the investigation of swelling. The disk-shaped specimens, size $3 \mathrm{~mm}$ in diameter and $0.25 \mathrm{~mm}$ in thickness, were cut and their surfaces were polished with diamond particles. The polished surface was covered with \#200 molybdenum mesh. The irradiation experiments of single-ion (only $\mathrm{Si}$ ion) beam and dual-ion (Si ion and helium ion) irradiation were performed at up to $3 \mathrm{dpa}$. The irradiation temperature ranged from room temperature to $1400^{\circ} \mathrm{C}$. The values of nominal flux and the helium over dpa were $1 \times 10^{-3} \mathrm{dpa} / \mathrm{s}$ and $60 \mathrm{appm} / \mathrm{dpa}$, respectively. The investigation of the swelling was performed by the step height method. The molybdenum mesh produced an unirradiated area on the surface. Steps were formed between the unirradiated and irradiated surfaces due to the swelling of irradiated SiC. Step heights were measured using an interferometric profilometry device (Micromap 128, Micromap Co., Tucson, Arizona, USA), and the amount of swelling of $\mathrm{SiC}$ was calculated following the method reported in the previous work. ${ }^{5)}$

\subsection{Microstructural investigation of $\mathrm{SiC} / \mathrm{SiC}$ compo- sites}

The reinforcement of the $\mathrm{SiC} / \mathrm{SiC}$ composites was attained by Tyranno-SA fiber (Ube Industries Co., Ube, Yamaguchi, Japan). This fiber is characterized by near-stoichiometric composition and high crystallinity. ${ }^{6}$ ) The composites were produced by the chemical vapor infiltration (CVI) method. Two kinds of interphases, namely pyrolytic carbon (PyC) layer and $\mathrm{C} / \mathrm{SiC}$ multilayer, were prepared. ${ }^{7)}$ The composites were then cut in square pieces and their surfaces were polished with diamond particles. The dimension of the specimens was $4 \times 2 \times 2 \mathrm{~mm}^{3}$. A surface normal to the fiber direction was selected for irradiation. The dual-ion irradiation was performed for these composites up to $100 \mathrm{dpa}$ at $1000^{\circ} \mathrm{C}$. The flux and helium over displacement damage ratios were $1 \times 10^{-3} \mathrm{dpa} / \mathrm{s}$ and $60 \mathrm{appm} / \mathrm{dpa}$, respectively. A focused ion beam (FIB) processing was used for the preparation of TEM specimens from the irradiated $\mathrm{SiC} / \mathrm{SiC}$ composites. $^{8)}$ The thinned foils were cut off from the materials and lifted using micro pick-up system. These foils were put on the carbon-film supported by copper grids. The microstructural investigation was carried out with a conventional JEOL JEM-2010 TEM.

\section{Results}

\subsection{Swelling of irradiated $\beta$-SiC}

Figure 3 shows the swelling of $\beta$-SiC under single-ion irradiations at several irradiation temperatures. In the initial damage accumulation range, the swelling increases with an increase in damage at all temperatures up to $1400^{\circ} \mathrm{C}$. The swelling saturates to $3 \mathrm{dpa}$ above $400^{\circ} \mathrm{C}$. The saturation could not be confirmed at $200^{\circ} \mathrm{C}$. At $60^{\circ} \mathrm{C}$, the saturation occurred at $1 \mathrm{dpa}$ and the swelling reached to approximately $10 \%$. The amorphization in CVD-SiC irradiated at $60^{\circ} \mathrm{C}$ was observed by TEM. It was considered that amorphization caused a large volume expansion at $60^{\circ} \mathrm{C}$. $^{5)}$ At temperatures higher than $400^{\circ} \mathrm{C}$, the saturation level of swelling tended to decrease with increasing in irradiation temperature. This trend continued up to $1400^{\circ} \mathrm{C}$. These swellings were considered to be due to the accumulation of point defects. The temperature range showing characteristic microstructural behaviors of $\mathrm{SiC}$ are considered to be divided into three stages, i.e., amorphization regime below $150^{\circ} \mathrm{C}$, point defect regime below $1000^{\circ} \mathrm{C}$, and void swelling regime above $1000^{\circ} \mathrm{C}^{7,9)}$

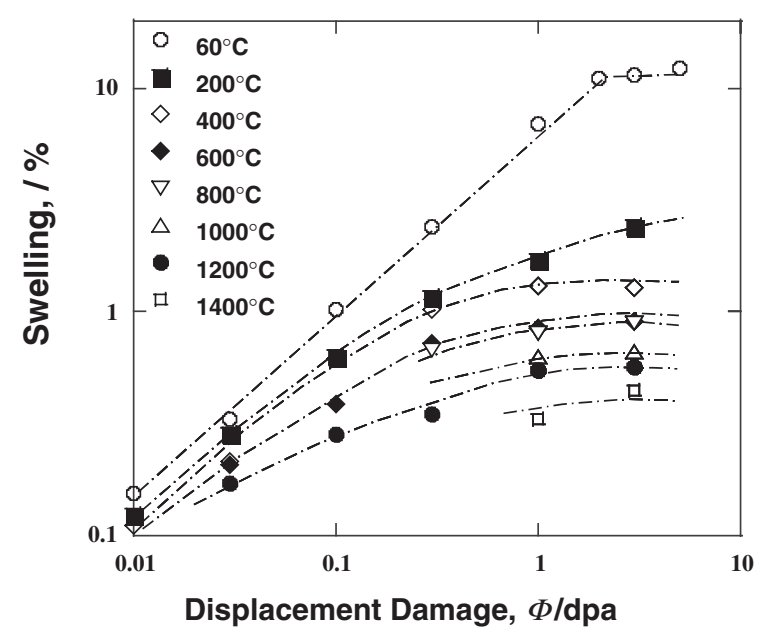

Fig. 3 Temperature and displacement damage dependencies of swelling in $\beta$-SiC under single-ion irradiation. 


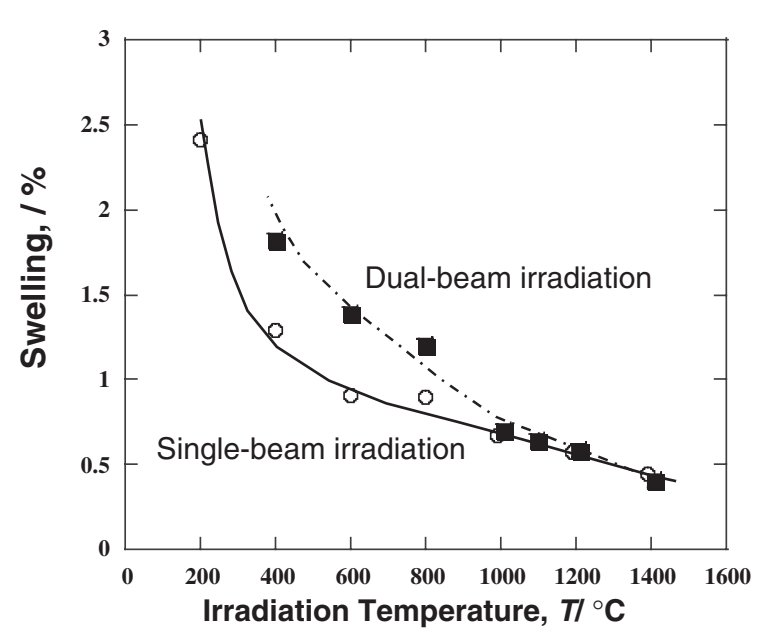

Fig. 4 Temperature dependence on swelling of SiC dual- and single-ion irradiated to 3 dpa.

The behavior of saturated swelling under the single-ion irradiation and the effect of helium under the dual-ion irradiation are shown in Fig. 4. The irradiation dose rate was $3 \mathrm{dpa}$ as in the Fig. 4. Under the single-ion irradiation, the saturated swelling decreased with an increase in the irradiation temperature up to $1400^{\circ} \mathrm{C}$. The trend observed in the dual-ion irradiated $\mathrm{SiC}$ was the same as that of the single-ion irradiated materials. But the absolute amounts of swellings were increased by the presence of helium on $\beta$-SiC below $1000^{\circ} \mathrm{C}$. However, this increase in swelling due to presence helium was not observed above $1000^{\circ} \mathrm{C}$. Thus, the interaction between displacement damage and helium seems to change above $1000^{\circ} \mathrm{C} .^{10)}$

\subsection{Microstructural evolution in $\mathrm{SiC} / \mathrm{SiC}$ composites under dual-ion irradiation}

Since $\mathrm{SiC}$ is a brittle material, $\mathrm{SiC}$ fiber reinforced $\mathrm{SiC}$ matrix composites have been developed to be employed as structural materials for fusion and fission systems. The fibers, matrix, and interphases in a $\mathrm{SiC} / \mathrm{SiC}$ composite are affected by irradiation or damage accumulation. The swelling of $\mathrm{SiC}$ fibers often determines total performance of $\mathrm{SiC} / \mathrm{SiC}$ composites. A highly crystallized $\mathrm{SiC}$ fiber was expected to have stable microstructure under irradiation environments; therefore, Tyranno-SA fibers having stoichiometric and crystallized structure were developed. Another important aspect was the performance of matrix/fiber interphase. In order to investigate the behavior of the interphase under irradiation environments, two kinds of interphases were developed. Figure 5 shows the TEM images of a pyrolytic carbon (PyC) monolayer interhase and a $\mathrm{C} / \mathrm{SiC}$ multilayer interphase. Figure 5(a) shows a $\mathrm{PyC}$ interphase that is approximately $600 \mathrm{~nm}$ thick. The $\mathrm{C} / \mathrm{SiC}$ multilayer in Fig. 5(b) has 5 thin carbon layers in the $\mathrm{SiC}$ matrix. Each carbon layer is approximately $25 \mathrm{~nm}$ thick and the diameter of SiC fibers is approximately $10 \mu \mathrm{m}$. Figure 6 shows a crosssectional TEM image of Tyranno-SA/multilayers/CVI-SiC composite after the dual-ion irradiation at $100 \mathrm{dpa}$ and $1000^{\circ} \mathrm{C}$. The helium implanted range was between $400 \mathrm{~nm}$ and $1900 \mathrm{~nm}$ depth from the specimen surface. Fractures and the shrinkage of Tyranno SA fiber were not observed. ${ }^{11)}$ The
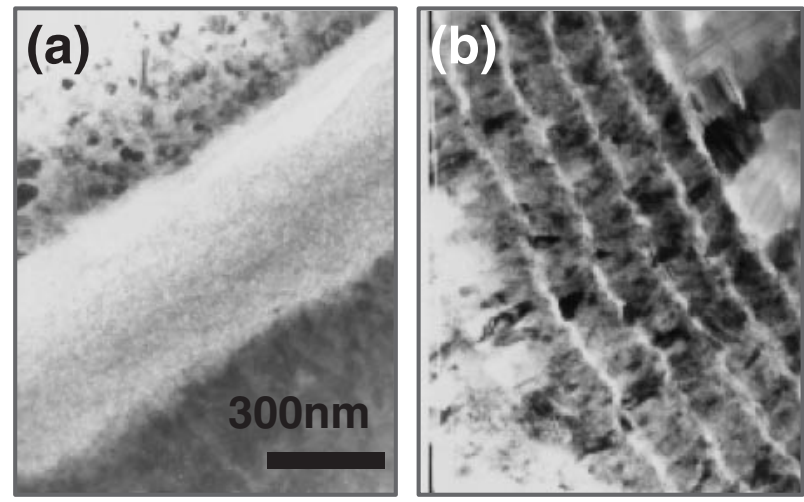

Fig. 5 TEM micrographs of interphases (a) pyrolytic carbon (PyC) layer (b) $\mathrm{C} / \mathrm{SiC}$ multilayer

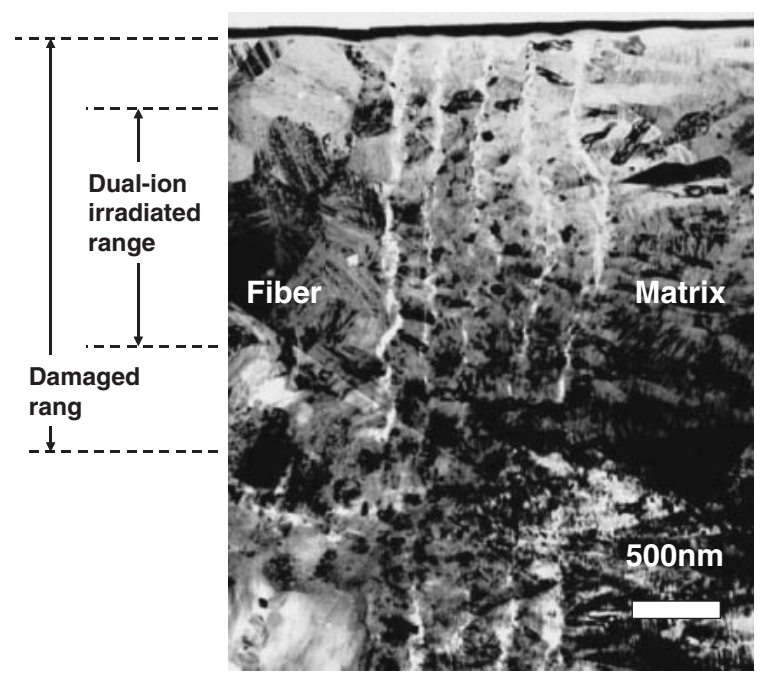

Fig. 6 A TEM image of the microstructure of Tyranno-SA/multilayer/ CVI-SiC composite dual-ion irradiated at $1000^{\circ} \mathrm{C}$ and $100 \mathrm{dpa}$.

dimensional changes of Tyranno SA fiber appeared to be the same as in the case of the CVI-SiC matrix. The multilayer interphase appeared to be stable because cracks and debondings of interphase were not observed. The thickness of each layer tended to decrease with an increase in the damage. This phenomenon suggests the possibility that a thin carbon layer may have been lost in a heavy dose irradiation environment. The cross-sectional TEM image of Tyranno$\mathrm{SA} / \mathrm{PyC} / \mathrm{CVI}-\mathrm{SiC}$ composites after the dual-ion irradiations of up to $100 \mathrm{dpa}$ at $1000^{\circ} \mathrm{C}$ is shown in Fig. 7. The irradiated range of the $\mathrm{PyC}$ interphase was apparently thicker than the unirradiated range. The border of irradiated and unirradaited range of interphases was broken during FIB processing in Fig. 7.

Although helium effects were not detected on the PyC interphase, implanted helium affected the microstructure of CVI-SiC matrix. Figure 8 shows a TEM image of the helium cavities in CVI-SiC matrix after the dual-ion irradiation at $1000^{\circ} \mathrm{C}$ and $100 \mathrm{dpa}$. The amount of cavity swelling in the CVI-SiC was calculated as approximately $0.3 \% .{ }^{12)}$ Some very fine cavities were observed on the grain boundaries on Tyranno-SA fibers, although, their quantitative analysis was difficult owing to their extremely small size. 


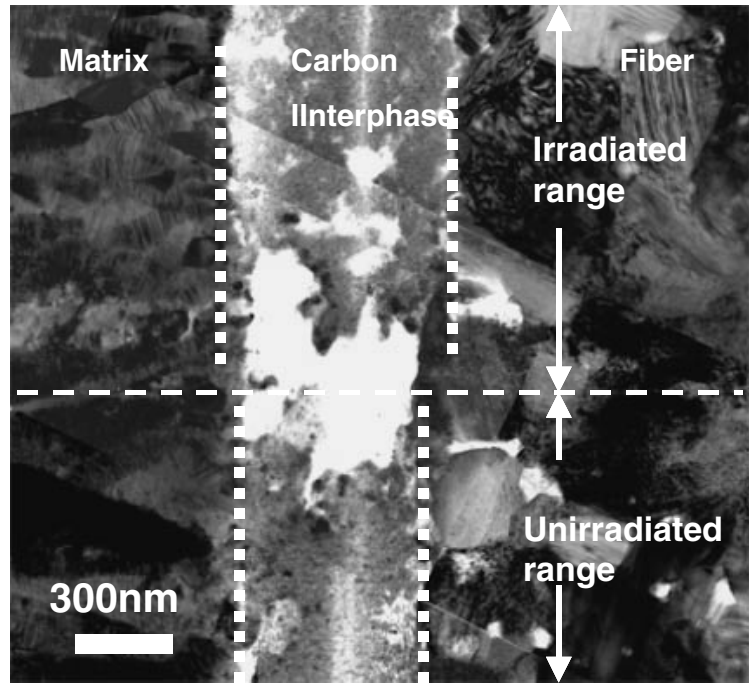

Fig. 7 Swelling of Pyrolytic carbon (PyC) interphase after dual-ion irradiation at $1000^{\circ} \mathrm{C}$ and $100 \mathrm{dpa}$.

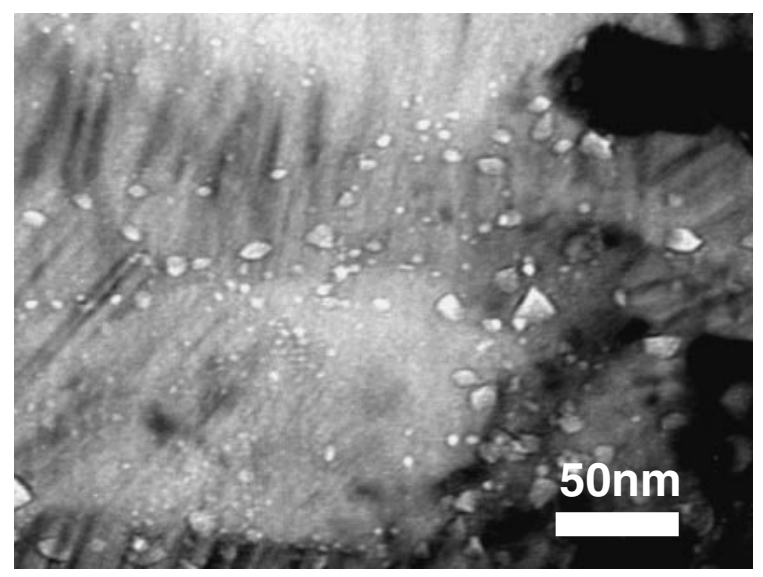

Fig. 8 TEM image of helium cavities in CVI-SiC dual-ion irradiated at $1000^{\circ} \mathrm{C}$ and $100 \mathrm{dpa}$.

\section{Discussion}

The most important reason for the degradation of mechanical properties of early $\mathrm{SiC} / \mathrm{SiC}$ composites was a large shrinkage of $\mathrm{SiC}$ fibers during the irradiation. The matrix and fiber debonding resulted in this reduction. ${ }^{13)}$ Since the amorphization of $\mathrm{SiC}$ leads to a large volume expansion of $\mathrm{SiC}$, the recent advanced $\mathrm{SiC}$ fibers including Tyranno-SA are crystallized very well to prevent the degradation of mechanical properties, which is due to the debondings at the carbon interphase. The swelling behaviors of CVI-SiC matrix and Tyranno-SA fiber were almost the same in this research. Although the crystallization of the amorphous $\mathrm{SiC}$ phase in fibers causes a large shrinkage of $\mathrm{SiC}$ fibers, the interphases fracture was not observed in this research. The crystallized $\mathrm{SiC}$ fibers such as Tyranno-SA, having stoichiometric composition, are considered not to shrink under the irradiation environment.

The helium effects on Tyranno-SA fibers were observed to be slightly different from those in the CVI-SiC matrix. Extremely small cavities were observed on the grain boundaries in Tyranno SA. Thus, helium migration and helium cavity formation were assumed to occur above $1000^{\circ} \mathrm{C}$. The helium effects on the amount of swelling disappeared above $1000^{\circ} \mathrm{C}$, as shown in Fig. 4. Below $800^{\circ} \mathrm{C}$, since the swelling of dual-ion irradiated $\mathrm{SiC}$ was larger than that of single-ion irradiated $\mathrm{SiC}$, the implanted helium was considered to be trapped at vacancies and prevent the progress of the recombination of interstitials and vacancies. The release of the trapped helium from vacancies is estimated to commence at $800^{\circ} \mathrm{C} .{ }^{14)}$ Thus, the void formation regime may start above $800^{\circ} \mathrm{C}$ and the helium cavity induced swelling may occur above $800^{\circ} \mathrm{C}$. The released helium is expected to migrate to grain boundaries and form helium cavities when the helium concentration on grain boundaries reaches a threshold. The CVI-SiC matrix was denser than the Tyranno-SA fibers, and had larger grains than Tyranno-SA fibers. Because the density of grain boundary on CVI-SiC matrix was less than that of the Tyranno-SA fibers, the density of trapping site for migrating helium in the CVI-SiC was also less than that of in the Tyranno-SA fibers. Thus, it was assumed that the number of helium cavities in the CVI$\mathrm{SiC}$ matrix was greater than that in the Tyranno-SA fibers. The interphases did not debond from matrix and fiber, and thus a significant degradation of mechanical properties was not expected to occur in the Tyrrano-SA reinforced composites. The increase in swelling due to helium cavity at $1000^{\circ} \mathrm{C}$ and 100 dpa was calculated to be approximately $0.3 \%$, which was not a significantly large expansion.

The mechanical properties of $\mathrm{SiC} / \mathrm{SiC}$ composites depend on the performance of interphases. In this research, the trends in microstructural behavior of carbon interphases under the irradiation environment were clarified. The construction of carbon interphases also need to be improved for further research in this field. This research showed that a volume expansion and a slight reduction in thickness of a carbon layer occur simultaneously. The former phenomenon is supposed to be the result of an increase in the lattice spacing of carbon layers, ${ }^{15)}$ while the reason for the latter phenomenon is unclear and the slight swelling of $\mathrm{SiC}$ or the irradiation-induced mixing of carbon are suggested to be responsible for it.

\section{Conclusion}

The dual-ion irradiation research for $\mathrm{SiC}$ and advanced $\mathrm{SiC} / \mathrm{SiC}$ composites was performed. The swelling of $\mathrm{SiC}$ depended on the irradiation dose, irradiation temperature, and implanted helium. The saturation swelling of $\mathrm{SiC}$ decreased with increasing in the irradiation temperature up to $1400^{\circ} \mathrm{C}$. The helium existence increased the swelling below $800^{\circ} \mathrm{C}$. Above $1000^{\circ} \mathrm{C}$, the helium effects were observed as the formation of helium cavities in $\mathrm{SiC}$. The advanced $\mathrm{SiC} / \mathrm{SiC}$ composite using the crystallized $\mathrm{SiC}$ fiber reinforcements seems to have a fair dimensional and microstructural stability at $1000^{\circ} \mathrm{C}$ after the dual-ion irradiation of up to $100 \mathrm{dpa}$ in this research.

\section{Acknowledgement}

The dual-beam ion irradiation experiment was carried out 
with the assistance of Drs. H. Sakasegawa, K. H. Park, K. Jimbo, H. Suzuki, and H. Ogiwara, Institute of Advanced Energy, Kyoto University. The authors would like to extend their heartiest thanks to Dr. Y. Katoh at ORNL for his useful discussion and help.

\section{REFERENCES}

1) R. H. Jones, L. L. Snead, A. Kohyama and P. Penici: Fusion Eng. Des. 41 (1998) 15-24.

2) P. Fenici, A. J. Frias Rebelo, R. H. Jones, A. Kohyama and L. L. Snead: J. Nucl. Mater. 258-263 (1998) 215-225.

3) S. Ishino: J. Nucl. Mater. 239 (1996) 24-33.

4) A. Kohyama, Y. Katoh, M. Ando and K. Jimbo: Fusion Eng. Des. 5152 (2000) 789-795.

5) H. Kishimoto, Y. Katoh, A. Kohyama and M. Ando: Effects of Radiation on Materials, ASTM STP-1405 (2001) 775-785.

6) T. Ishikawa, Y. Kohtoku, K. Kumagawa, T. Yamamura and T. Nagakawa: Nature 391 (1998) 773-775.
7) L. L. Snead, M. C. Osborne, R. A. Lowden, J. Strizak, R. J. Shinavski, K. L. More, W. S. Eatherly, J. Bailey and A. M. Williams: J. Nucl. Mater. 253 (1998) 20-30.

8) Y. Katoh, A. Kohyama and T. Hinoki: Eur. Conf. Comp. Mater. Sci. Technol. Appl. 4 (1998) 351-357.

9) S. Kondo, K. H. Park, Y. Katoh and A. Kohyama: Fusion Sci. Technol. 44 (2003) 181-185.

10) H. Kishimoto, Y. Katoh, K. H. Park, S. Kondo and A. Kohyama: Advanced SiC/SiC Ceramic Composites: Developments and Applications in Energy Systems, Ceram. Trans. 144 (2002) 343-352.

11) H. Kishimoto, Y. Katoh and A. Kohyama: J. Nucl. Mater. 307-311 (2002) 1130-1134.

12) S. Nogami, A. Hasegawa, K. Abe, T. Taguchi and R. Yamada: J. Nucl. Mater. 283-287 (2000) 268-272.

13) Y. Katoh, M. Kotani, H. Kishimoto, W. Yang and A. Kohyama: J. Nucl. Mater. 289 (2001) 42-47.

14) A. Hasegawa, B. M. Oliver, S. Nogami, K. Abe and R. H. Jones: J. Nucl. Mater. 283-287 (2000) 811-815.

15) Y. Katoh, T. Hinoki, A. Kohyama, T. Shibayama and H. Takahashi: Ceramic Engineering and Science Proceedings 20 (1999) 325-332. 